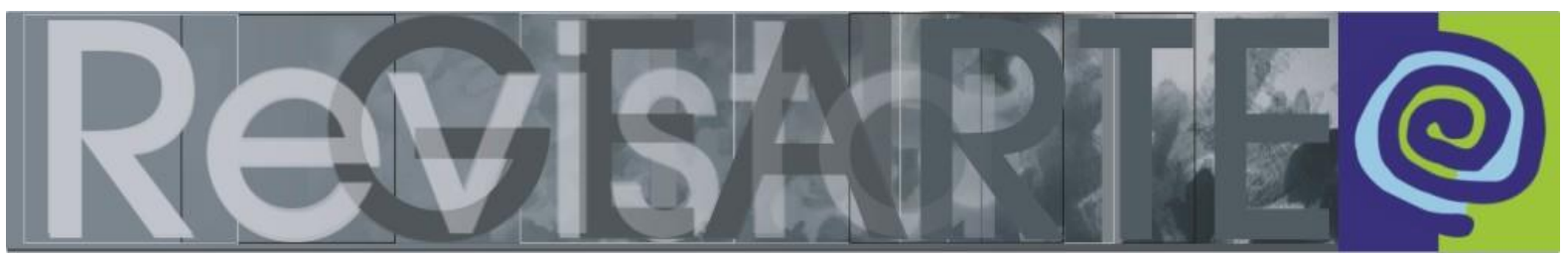

ISSN 2357-9854 | e-ISSN 2596-3198 (online)

\title{
Arte na Pedagogia
}

Ana Mae Barbosa

(Universidade de São Paulo — USP/Universidade Anhembi

Morumbi — UAM, São Paulo/SP, Brasil)

Aprender é ter uma experiência. 'A arte une mais que experiências de outra natureza. São as relações de fazer e padecer, e a energia de ida e vinda que fazem com que a experiência da Arte seja uma experiência renovadora e constantemente renovável'.

John Dewey

O confinamento que estamos mantendo para evitar o contágio pelo coronavírus amplia o tempo, mas apressa os prazos. Queremos terminar o que estávamos fazendo antes, especialmente se podemos fazer o que tem que ser feito em nossas casas, como escrever, por exemplo.

Aos 83 anos, quando nesta pressão do confinamento me pedem algum texto com prazo de entrega em poucos dias, eu penso duas vezes: - Se eu soubesse que ia morrer amanhã, correria para escrever este texto?

No caso do convite de Mirian e Lucia, a resposta que me dei foi um rápido e alto sim, sim eu escreveria.

Primeiro pela importância do tema Arte na Pedagogia, depois, porque admiro o trabalho deste grupo GPAP - Grupo de Pesquisa Arte na Pedagogia, coordenado por Mirian e Lucia. Trata-se de um trabalho contínuo e consolidado em muitos textos, congressos e atividades pedagógicas variadas.

Sou entusiasta da formação de Grupos de Pesquisa e de Estudos em programas de Pós-Graduação. Acho mesmo que as experiências com os grupos de pesquisas nas universidades poderão servir como exemplo para as reformas urgentes que o sistema universitário necessita para se tornar mais democrático e melhor servir à ansiedade de aprendizagem dos jovens de hoje. 


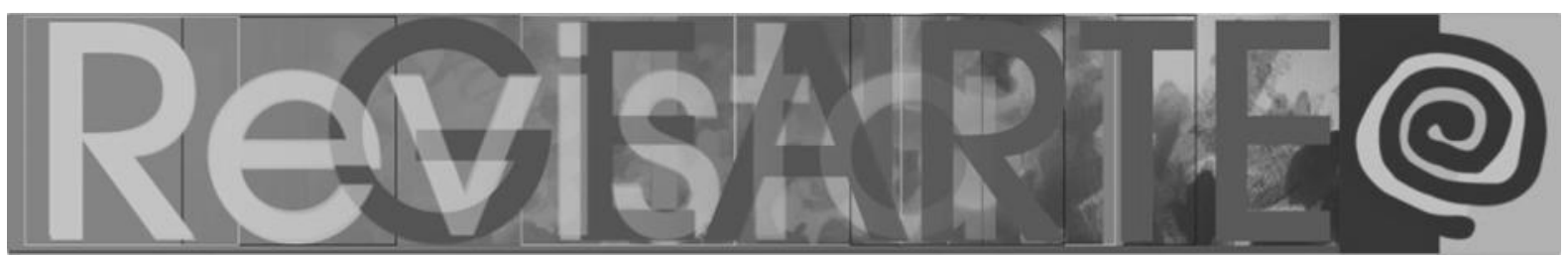

Temos no Brasil uma universidade muito boa, com excelentes professores e alunos/as e um processo democrático de acesso que está diminuindo a desigualdade social. $\mathrm{O}$ que nos falta agora é gestão curricular e o entendimento de que as Humanidades alimentam a plasticidade cerebral e a potência da cognição humana, contribuindo para a aprendizagem de outras áreas, da Agricultura às Ciências.

Nos Grupos de Pesquisa e de Estudos os/as alunos/as podem entrar e sair quando querem, não são obrigados a permanecer. Sou até mesmo contra disciplinas obrigatórias na Pós-Graduação. Cada aluno junto com seu orientador ou orientadora deveria construir seu próprio cardápio de disciplinas (o que já é feito em muitas universidades) e os temas das teses e dissertações poderiam se estruturar em torno de questão ampla, e cada membro do Grupo tomar a si a pesquisa de um dos aspectos do problema, o que as agências de Pesquisa em geral priorizam. Piaget foi um dos primeiros a trabalhar com esse modelo guardachuva de organização integrada de pesquisas.

A luta pela Arte na Pedagogia começou antes que os cursos de formação de Professores para as quatro primeiras séries, antigamente designado Ensino Primário, passasse para a Universidade.

O/A professor/a primário/a era formado/a em nível de Ensino Médio. Eu fiz o que chamavam no meu tempo o ensino médio Pedagógico ou como a Escola Nova chamava: Escola Normal. Arte não era atividade, muito menos disciplina obrigatória. Tínhamos Trabalhos Manuais no currículo. O objetivo dos Trabalhos Manuais era fazer cartazes, imagens, jogos e outros materiais para darmos aula no nosso estágio.

Minha professora, Perpedigna, era muito frustrada com as limitações dos Trabalhos Manuais. Era amiga de Noemia Varela e frequentava a Escolinha de Arte do Recife. Foi uma das criadoras do DECA - Departamento de Cultura da Secretaria de Educação do Recife e conseguiu levar para dar aulas às professoras 


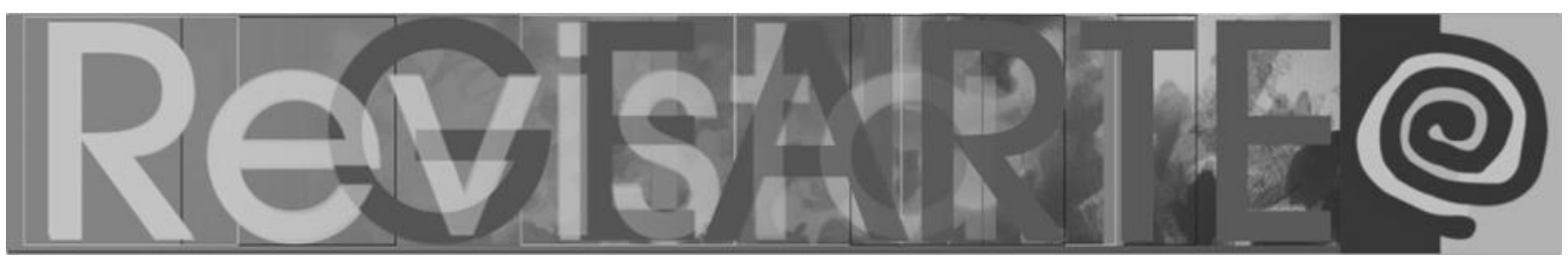

das Escolas Públicas gente importante como Ariano Suassuna, Hermilo Borba Filho (do Teatro), Paulo Freire e a turma da Escola de Belas Artes do Recife, que foi uma excelente escola do seu início em 1932/33 até os fins da década de 1950. Vicente do Rego Monteiro1, que foi professor da Escola de Belas Artes, organizou a primeira exposição no Brasil dos Modernistas europeus da Escola de Paris no Recife, que sempre foi um centro cultural muito buliçoso. Portanto quando a Escola de Belas Artes do Recife foi criada, os pernambucanos já tinham visto Picasso na exposição do Teatro Santa Isabel. Depois a exposição viajou para Rio de Janeiro e São Paulo.

Mas a luta sistematizada por introduzir Arte na Pedagogia começou ainda nos Cursos de Segundo Grau (Ensino Médio) nos Centros Especializados de Formação e de Apoio ao Magistério (CEFAM), pela incansável ação de Mariazinha Fusari. No tempo em que dirigi o MAC - Museu de Arte Contemporânea -, me aliei a Mariazinha e organizamos um programa em um CEFAM, coordenado por Christina Rizzi, se não estou enganada, enquanto Mariazinha em um projeto financiado pela FAPESP coordenava outro CEFAM. Visitamos o projeto uma da outra, nos animando mutuamente atuando em sintonia. Mariazinha foi muito feliz também na implantação da Arte na Pedagogia da USP no momento difícil da redemocratização do país depois da ditadura.

Louvo Mirian por continuar a luta de sua orientadora, que tanta falta faz, afetiva e professional e louvo Lucia e todo o GPAP por dar tanta força a esta luta agora nas Universidades e Institutos Federais.

Enquanto dava aula remota aos meus alunos de Mestrado e Doutorado em Design, Mirian me enviou um e-mail dizendo "não podemos passar do prazo" e o prazo é hoje, é agora. "Estamos todas correndo atrás do tempo", me diz Mirian em um afetivo e-mail.

Cada texto merece atenção especial. Encantei-me com o fato de que todos os artigos constroem a teoria a partir da prática, como diria Gramsci. Cada um 


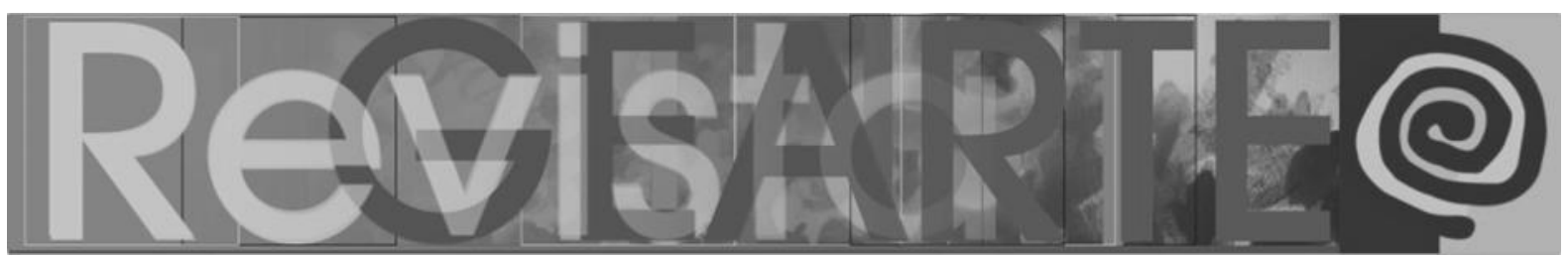

deles surge da inventividade dos/das professores/as em sala de aula e da análise posterior extraindo sentidos da ação. Com verba das universidades ou não, as aulas de Arte aqui descritas e analisadas são direcionadas a provocar o processo criador embebido em cultura em geral e em cultura ao redor.

As teias interdisciplinares deste livro que tem um universo geopolítico tão diversificado são muito bem tecidas pela excelente articulação teórica de "múltiplos recortes de formações estéticas/culturais" (Fabiana Souto Lima Vidal). O culturalismo deste livro vai desde o artigo de Analice Dutra Pillar e Rosana Fachel de Medeiros, que explora várias culturas através da confecção de bonecas "Abayomi, a boneca negra feita com cinco nós, a qual historicamente foi criada pelas mães africanas, que vieram nos navios da diáspora negra, com tiras de tecidos de suas saias", às bonecas da indústria cultural. Fiquei entusiasmada também com o excelente programa Territórios Educativos, promovido pela Próreitoria de Graduação da Universidade Federal de Juiz de Fora, com possibilidade de viagem do grupo de estudantes ao Rio de Janeiro e São Paulo para visitar exposições e instituições culturais (Fracione Oliveira Carvalho). Ainda sobre os códigos marginalizados temos o trabalho muito interessante sobre a Oficina de Cordel (Ana Cristina Moraes).

O contato com o código erudito, europeu e norte-americano branco, que está no topo da pretendida globalização, sozinho, não prepara o leitor multicultural, mas é necessário também o conhecimento de outros códigos, menos poderosos, mas muito significativos para o entendimento do mundo, como os códigos da cultura africana, indígena, asiática, feminina, do cotidiano, do design, dos homossexuais, do povo, etc.

Excluir o popular é apresentar um conceito classista de Arte, da mesma maneira que é sexista um professor que apresente apenas obras de artistas homens aos/às seus/suas alunos/as, pois está implicitamente dizendo a eles que o bom artista é sempre o homem. 


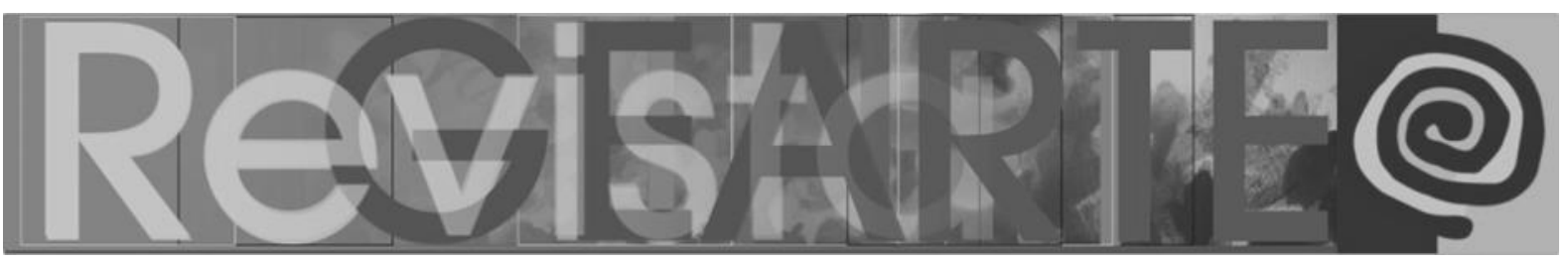

Contudo, a decolonização não significa desprezar o código europeu, mas se recusar a elegê-lo como modelo único, embora seja importante, para todas as classes sociais estudá-lo e conhecê-lo, pois é o código do poder, e sem conhecer os códigos do poder ninguém chega a ele muito menos o transforma (SMITH, 1991).

O texto de Jessica Makino é um valioso roteiro para um passeio pelas instituições dedicadas principalmente à música erudita e às artes visuais eruditas, que os alunos precisam conhecer para serem considerados alfabetizados culturalmente.

Também de "expedição artística" ao atelier do artista Ernesto Ferro fala Lucia Lombardi. Ernesto Ferro é um verdadeiro parceiro do processo de ensinar/aprender pois abre seu atelier à noite só para receber a turma da Pedagogia, que exercita não só o ver analiticamente, mas também o fazer com o artista.

Mirian Celeste Martins salienta principalmente o desenvolvimento da capacidade perceptiva das/os "aspirantes à professor/a" ao verem as crianças fazendo seus desenhos. Ver fazendo é um requisito atual das pesquisas sobre desenho infantil. $\mathrm{Na}$ década de 1980 os pesquisadores intransigentes desqualificavam as pesquisas de Lowenfeld, porque foram feitas em coleções de desenho infantil, que ele não viu as crianças fazerem. Hoje volta-se a valorizá-lo pela abrangência de sua pesquisa, que examina desenhos da infância à adolescência. Os pesquisadores de desenho infantil que se seguiram, como produziram para seus doutorados, não puderam se dar ao luxo de serem tão abrangentes e estudaram etapas circunscritas e recortadas do desenvolvimento gráfico e plástico em geral, vendo-os fazer, analisando os gestos, a conversa durante a produção, as idas e vindas, as transformações dos traços etc. Os dois enfoques analisados conjuntamente deram resposta a muitos questionamentos dos professores de Arte da minha geração. 


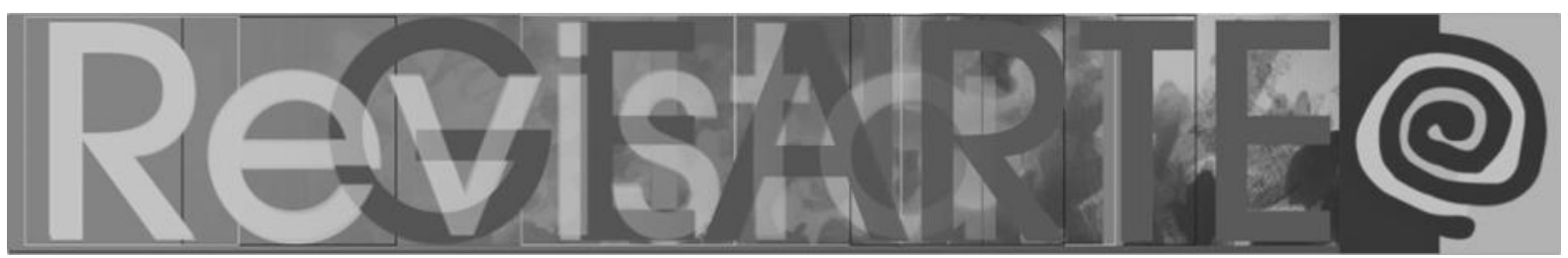

Pensando nos dois textos, o de Mirian e o de Lucia, imagino que a leitura dos dois em conjunto corresponde à abordagem metodológica de Yunkaporta (apud BEDESCHI, 2020), um importante pesquisador Maori do Ensino da Arte da Nova Zelândia, onde a Arte/Educação tem se desenvolvido muito ultimamente, o qual diz que aprendemos fazendo sozinhos, vendo fazer e fazendo junto com os outros.

Se comprova neste livro, com Luciana Esmeralda Ostetto e Monique Traverzim, a teoria de que nos últimos anos os especialistas em Educação Infantil (professores das crianças e professores dos professores) são os que mais conseguiram dar dignidade à sua área, mais que nós, os Universitários em geral, que estamos sendo caluniados e desqualificados, apesar de excelentes experiências como as transformadoras da UNIFESP de Guarulhos, relatadas pela competente e dedicada professora Betânia Libâneo Dantas.

Luciana Esmeralda Ostetto reclama principalmente o fato de as ementas de Arte nos Cursos de Pedagogia não tratarem da evolução do desenho infantil. Concordo com ela e acrescento que também é preciso conhecer as fases de evolução do entendimento das imagens para não se cometer o erro de insistir em dar obras de Miró para as crianças de três e quatro anos lerem ou interpretarem, quando a primeira fase de apreensão da imagem é a narrativa. O indicado nessa fase são obras figurativas, que possam servir de base para a criança inventar histórias baseadas em suas experiências, desejos e realidades. Muitas vezes inclusive uma mesma imagem serve de base para diferentes narrativas, dependendo da imaginação fértil e integradora da criança.

Por falar em narrativa, a carta na qual Anna Rita Araújo de lá dos Estados Unidos, onde está vivendo temporariamente, reconta uma das histórias preferidas de sua ex-orientadora, minha amiga querida, Regina Machado, me emocionou muito por ter me provocado um acesso de conscientização acerca da felicidade que tenho de ter entre vocês escritores e escritoras deste livro um amigo e muitas amigas próximas, que alimentam e energizam minha vida. Também fico feliz por encontrar pela primeira vez através de textos outros Arte/Educadores que eu não 


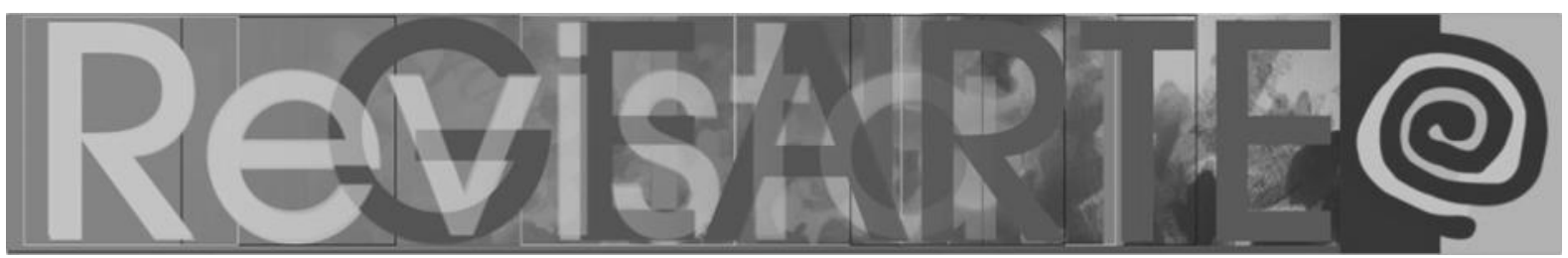

conhecia, inteligentes, competentes e com clareza teórica e prática eficiente, que espero se tornem meu amigo e minhas amigas.

Quase todos os capítulos reclamam por mais Arte na Pedagogia, cujo objetivo não é só fazer com que os estudantes de Pedagogia aprendam a dar aulas de Arte, mas principalmente desenvolver as capacidades criadoras, comunicativas, expressivas e críticas dos próprios estudantes que vão ser professores/as.

Como diz Ana Paula Abrahamian acerca da Dança, criticando os programas que apenas perpetuam "práticas cristalizadas das dancinhas escolares, com seus movimentos estereotipados e repetitivos que são produzidas nas diferentes comemorações durante todo o ano letivo, que se inicia no Carnaval e finaliza no Natal", o importante é que os estudantes de Pedagogia desmistifiquem "o discurso dos corpos ideais para o trânsito com a perspectiva dos corpos-ideias".

Além de todas as Artes com professores orientadores especializados, os/as estudantes de Pedagogia precisam de Filosofia e História.

O filósofo da Arte/Educação no Brasil é Fernando Azevedo. Mas ele é também historiador e principalmente é feminista. Em nossa sociedade nada é mais valioso que um homem feminista; talvez esta avaliação seja resquício da minha educação machista. Em Filosofia e História sua bússola é Foucault. Fernando, como ninguém que eu conheça, consegue extrair de fatos marginais uma interpretação abrangente do ponto de vista de significado, tempo e espaço. A ele devemos textos indispensáveis como o que publica neste livro tratando das ideias, ações e ocorrências factuais articuláveis entre Noemia Varela e Nise da Silveira, culminando com uma homenagem as professoras de hoje da sexagenária Escola Ulisses Pernambucano de Recife, através das imagens da significativa exposição de trabalhos de alunos com dificuldades intelectuais ou mentais que elas organizaram no MAMAM.

O texto de Ana Luiza Ruschel Nunes, nossa combativa, eficiente e querida ex-presidente da FAEB (Federação de Arte/Educadores do Brasil), em parceria 


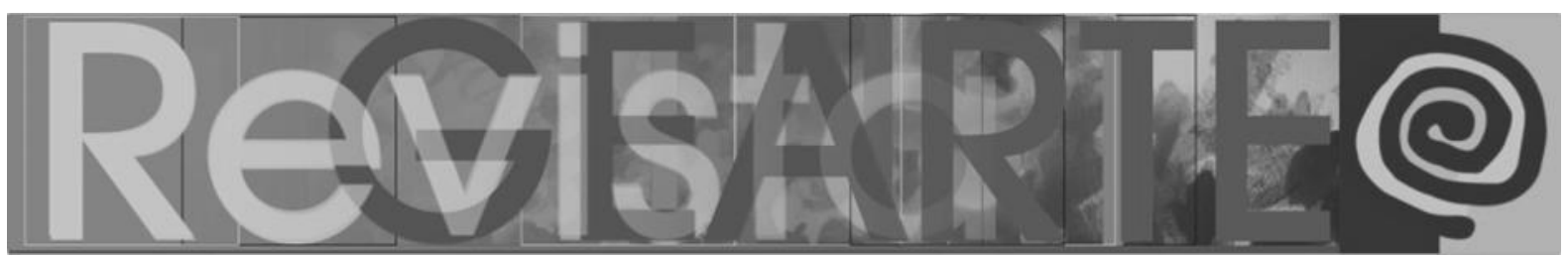

com Andréia Bulaty, é muito importante para a História do Ensino da Arte na Pedagogia, pois fará um balanço do que se tem escrito sobre o tema. Como já disse, História é fundamental para termos consciência da importância de nossa profissão, que nem sempre foi maltratada. Por exemplo, Marcia Strazzacappa, no importante projeto que conheci na UNICAMP, apontava - e que Luciane Germano Goldberg também aponta - é para o prazer da arte ao escolher uma imagem de um brinquedo para analisar com os/as alunos/as. É uma imagem que exala prazer e memória do prazer.

O prazer é muito importante: aprender a ter prazer com a arte, com o contato, a compreensão, a contaminação, a intimidade das artes amplia a capacidade de viver com mais intensidade.

Como o critério de Beleza não dá conta de explicar a espécie de prazer que a experiência da Arte Contemporânea nos provoca (George Grosz, Max Ernst apud DANTO, 2005).

Samuel Messick e Philip Jackson propunham que diante do objeto inquiríssemos se ele representava uma experiência de: surpresa, satisfação, estimulação e saboreio, se quisermos avaliar o grau de prazer que uma obra de arte nos provoca.

Qual o grau de surpresa que a obra provoca? Por quê? Esta pergunta verificaria o grau de originalidade, de inusualidade do objeto frente às normas conhecidas. O choque de reconhecimento elimina a possibilidade da obviedade do objeto e afirma o seu poder de alterar a maneira convencional do observador ver e pensar as coisas. Anne Bamford intitula seu livro sobre o impacto das Artes na Educação de "O Fator WOW". A diferença que a Arte provoca é tornar você capaz de dizer diante dela WOW!!!!. Já a pergunta pela espécie de satisfação que a obra dá aponta a verificação de onde e de como ela responde ao contexto, sendo apropriada à sensibilidade do tempo e espaço em que está sendo examinada. 


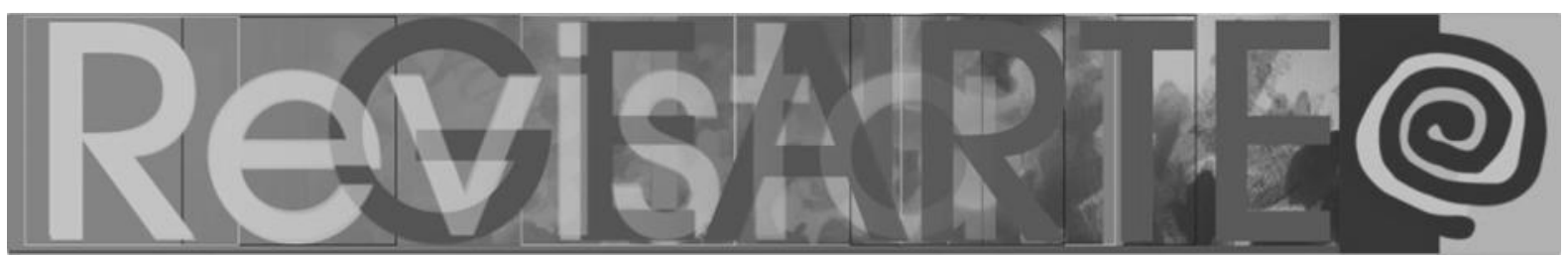

Surpresa e satisfação são critérios aparentemente opostos, que se imbricam dialeticamente. Enquanto a surpresa demonstra a inusualidade do objeto e exige que o observador assimile o objeto para fazê-lo parte do seu mundo cognoscível, a satisfação que o objeto provoca demonstra a sua adequação ao mundo conhecido do observador, obrigando-o a tomar consciência deste mundo.

O critério de estimulação transformadora instiga à pergunta: esta obra muda alguma coisa na forma de dizer o que ela pretende dizer? Esta obra muda algo em mim? Esta obra muda algum conceito de arte? Esta obra opera alguma mudança na arte hoje? Qual a mudança que ela significa para a arte de outros tempos ou para arte em diversos outros tempos?

Por último, temos o critério mais inusual: a ideia de que a obra de arte deve ser saboreada, que requer para isto uma concentração de significados que advém de sua complexidade. A obra para ter qualidade estética deve ter o poder de sumarizar múltiplos significados. Daí se conclui que uma obra de arte de significado único, evidentemente percebido à primeira olhada, não tem a qualidade estética de saboreio para o espectador. Ele a deglute de imediato. O saboreio advém do poder de sumarizar da obra, da sua condensação, que implica a possibilidade de o observador exercitar sua capacidade de criar múltiplas interpretações. A arte exige hoje do espectador flexibilidade para compreender e avaliar uma multiplicidade de códigos culturais.

Como o texto de Olga Egas é uma declaração de amor à nossa profissão, peço permissão para citá-la fazendo minhas as suas palavras: "...sinto-me imensamente feliz por ser professora há tanto tempo... Foi, para minha vida, a escolha certa!".

\section{Nota}

1 Sobre Vicente Rego Monteiro ler: Moacir dos Anjos Jr.; Jorge Ventura Morais em Picasso 'visita' o Recife: a exposição da Escola de Paris em março de 1930. "Tendo vivido em Paris entre 1911 e 1915, volta ao Brasil após a deflagração da Primeira Guerra Mundial, aos 15 anos de idade e já com a experiência de ter frequentado várias escolas de pintura (entre elas a Academia Julian e a Academia Colarossi) e de ter participado, em 1913, do Salon des Indépendants" (MONTEIRO, 1969). Disponível 


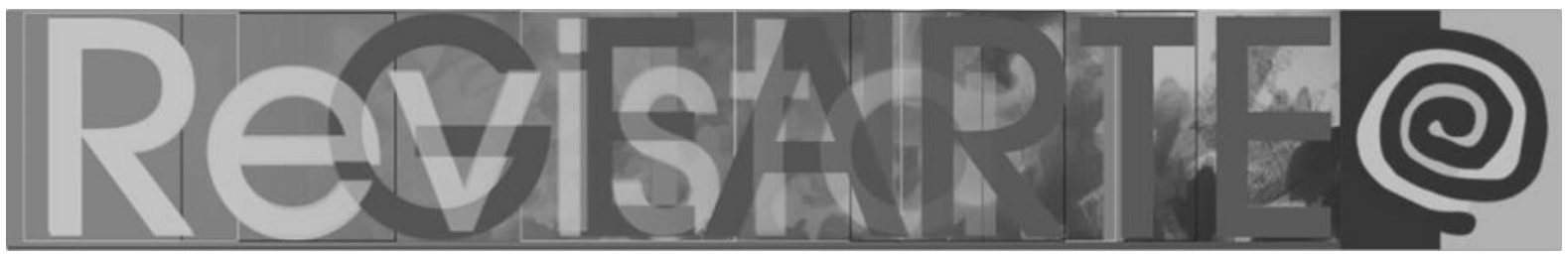

em <https://www.scielo.br/scielo.php?script=sci_arttext\&pid=S0103-40141998000300027>. Acesso em 07 maio 2020.

\section{Referências}

ANJOS, Moacir; MORAIS, Jorge Ventura. Picasso 'visita' o Recife: a exposição da Escola de Paris em março de 1930. Disponível em: <https://www.scielo.br/scielo.php?script=sci_arttext\& pid=S0103-40141998000300027 >. Acesso em: 7 maio 2020.

BAMFORD, Anne. The WOW Factor. New York: WAXMANN, 2006.

DANTO, Arthur. Unnatural wonders. New York: Farrar, Straus, Giroux, 2005.

SMITH, Ralph A. Cultural literacy. Washington: National Endowment of Arts, 1991.

\section{Ana Mae Barbosa}

Professora Titular Sênior da Universidade de São Paulo e professora da Universidade Anhembi Morumbi. Graduada em Direito pela Universidade Federal de Pernambuco. Mestre em Art Education pela Southern Conncticut State College e Doutora em Humanistic Education pela Boston University.

ORCID: https://orcid.org/0000-0002-4966-2043

E-mail: anamaebarbosa@gmail.com

Currículo: http://lattes.cnpq.br/1650414096296319

Recebido em 22 de fevereiro de 2021 Aceito em 20 de abril de 2021 